\title{
O MÍNIMO EXISTENCIAL SOB A ÓTICA DA TEORIA DOS SISTEMAS DE NIKLAS LUHMANN
}

\author{
Márcio Alexandre Diniz Cabral ${ }^{1}$
}

\section{RESUMO}

O presente estudo examina os fundamentos da teoria dos sistemas idealizada pelo sociólogo alemão Niklas Luhmann aplicável a uma sociedade moderna com existência de comunicação, sistemas, entornos, constantes irritações e observações entre os inúmeros sistemas, sobretudo as expectativas normativas, adotando resistência contrafática sem deixar de mencionar a autopoiesis, baseada na existência de um código binário com a característica de sistema operacionalmente fechado e cognitivamente aberto, com a Constituição como resultado do acoplamento estrutural entre os sistemas do Direito e da Política e a compreensão do instituto do mínimo existencial, baseado em preceitos advindos da própria Constituição.

Palavras-chave: Sistemas. Autopoiese. Constituição. Acoplamento estrutural. Mínimo existencial.

\section{THE MINIMUM EXISTENCIAL FROM THE PERSPECTIVE OF THE SYSTEMS THEORY OF NIKLAS LUHMANN}

\begin{abstract}
The present research examines the foundations of the systems theory of the German sociologist Niklas Luhmann and their applicability to a modern society with existence of communication, systems, environments, constant irritations and observations among the numerous systems, especially normative expectations, adopting counterfactual resistance without leaving To mention autopoiesis, based on the existence of a binary code with the characteristic of an operationally closed and cognitively open system, with the Constitution as a result of the structural coupling between the systems of Law and Politics and the understanding of the institute of the existential minimum, based on Precepts from the Constitution itself.
\end{abstract}

Keywords: Systems. Autopoiesis. Constitution. Structural coupling. Minimum existencial

\section{INTRODUÇÃO}

O presente trabalho busca, sem a ambição de esgotar o assunto, discorrer sobre aspectos considerados relevantes sobre a teoria dos sistemas aperfeiçoada por Niklas

\footnotetext{
${ }^{1}$ Mestre em Direito, Processo e Cidadania pela Universidade Católica de Pernambuco- UNICAP, Especialista em Direito Público e Privado pela Faculdade de Direito Prof. Damásio de Jesus, São Paulo-SP e Especialista em Direito Civil e Processo Civil pela Universidade Católica Dom Bosco, Campo Grande, Mato Grosso do Sul-MS.
} 
Luhmann através da ênfase conferida aos sistemas estruturados e a noção de mundo circundante, com a constatação de que o referido autor encara o homem concreto como um elemento fora do sistema maior, chamado sociedade, dotado dos atributos da contingência e complexidade e da necessidade de especificações e simplificações com intensificação de tais elementos na sociedade contemporânea, onde salta aos olhos a análise dos sistemas autopoiéticos baseados nas características da autoreferenciabilidade e fechamento operacional.

Importante destacar também o papel das influências externas advindas do entorno ou ambiente circundante, também formado por outros sistemas autopoiéticos, o que equivale dizer que o fechamento operacional não transforma o sistema num conjunto de elementos intrasistêmicos isolado, pois tais irritações estão sujeitas a uma operação de diferenciação do mundo circundante baseada num código binário com função de imprimir seletividade, diminuição da complexidade com base em dados pertencentes ao interior do respectivo sistema, o que culmina com escolhas de certas possibilidades e possibilita a feição de ser, ao mesmo tempo, fechado e aberto, dotado de formulação de sua própria estrutura e elementos, com possibilidade de eliminações em momento anterior cujo resultado maior é ser um sistema cognitivamente aberto a estímulos e ruídos advindos do mundo circundante ou entorno e alimentação de seus elementos internos.

Neste contexto, a finalidade reside em analisar a visão da teoria dos sistemas quanto ao papel da Constituição e seu efeito conformador, não apenas como elemento de validade das demais normas do ordenamento infraconstitucional tal como se encara numa concepção mais usual, mas também a função de fundamentação de um sistema autopoiético com a criação de um código binário específico, o que influencia diretamente na compreensão sistêmica do mínimo existencial, análise de seus controversos contornos qualitativos e quantitativos quando da aferição da parcela considerada fundamental dos direitos sociais amparados em nosso ordenamento.

\section{CONCEPÇÃO DE SOCIEDADE E A VISÃO LUHMANIANA}

A análise do direito sob a ótica luhmaninana busca se distanciar de uma definição teórica e busca uma visão baseada na sociologia para o estudo de problemas através de uma visão peculiar e inovadora.

Luhmann considera que a sociedade pode ser definida como um sistema estruturado de condutas e ações inter-relacionadas e cujo papel do homem é o de estar fora de tal sistema, restando ao mesmo fazer parte do mundo circundante.

Nas palavras de Tércio Sampaio Ferraz (LUHMANN, 1980: 3), quando da apresentação de uma tradução de uma obra de Luhmann "a conexão de sentido que liga as ações do sistema social não coincide com a conexão de sentido das ações do ser humano concreto".

A sociedade está para o homem como um problema a ser resolvido e vice-versa, restando as qualidades de complexidade e contingência como melhores adjetivações para a relação em tela, o que não impede a coexistência, pois é fato que o homem necessita da sociedade para existir, apesar de não fazer parte dela. 
O direito surge como um instrumento cuja finalidade é a fixação de limites toleráveis de contatos e de estabilização de expectativas para conformar as várias possibilidades de condutas individuais.

Luhmann, como já assentado acima, interpreta a sociedade como um sistema e, para tanto, se utiliza de mudanças paradigmáticas que ocorreram nos anos 70 e 80, em função de estudos e descobertas oriundos das ciências exatas e biológicas, o que passou a equivaler a uma teoria geral dos sistemas, apresentando-se hoje como uma teoria baseada nos pilares da autopoiesis, autoreferenciabilidade e fechamento operacional

Enquanto Maturana e Varela restringiram sua teoria e o respectivo conceito da autopoiesis a sistemas vivos, Luhmann promoveu uma ampliação de sua aplicabilidade para todos os sistemas que preenchessem os requisitos da constatação de funcionamento específico e exclusivo, o que, na visão do autor, compreendia os sistemas sociais e os sistemas psíquicos.

Neste contexto, as operações básicas dos sistemas sociais ocorrem na modalidade das comunicações e ambos operam fechados, no sentido de que as operações internas e anteriores são produtoras dos novos elementos do sistema, assim como são uma condição para a existência e manutenção de futuras operações.

Segundo Luhmann, essa hipótese de fechamento seria conditio sinequa non para a existência da autonomia do sistema, pois seria impossível atuar fora das suas fronteiras, merecendo a ressalva de que o reconhecimento da autopoiesis nos leva à noção de autonomia, mas não implica na negativa de relevância do meio para o sistema, pois a inexistência deste, implicaria na consequente inexistência de um sistema.

A teoria lumaniana também encontra destaque no reconhecimento pelo seu autor das transformações empreendidas pela modernidade e pelo incremento da complexidade no estágio atual, pois seu aumento gerou o surgimento de diversos subsistemas criados a partir de especificações e diferenciações funcionais semelhantes entre si, principalmente, pelo chamado fechamento operacional.

A entrada para a modernidade e a concepção individualista marca um intervalo cuja característica maior, como já dito, é o incremento da complexidade, o que nas palavras de Marilena Chauí pode ser sintetizado da seguinte maneira:

O que conhecemos com o nome de modernidade começa quando desaparece uma ideia de ordem universal - seja ela imanente ao cosmos ou transcendente a ele. Em outras palavras, a modernidade começa quando termina a ideia de "mundo" (espaço infinito, dotado de centro e de periferia e de "lugares" naturais) e de hierarquia natural dos seres, cedendo para as ideias de universo infinito, desprovido de centro e de periferia, e de individuo livre, átomo no interior da natureza e para o qual já não possuímos a definição prévia de seu lugar próprio e, portanto, de suas virtudes políticas (CHAUÍ, 1992, p. 350).

A teoria dos sistemas sociais possui como foco principal a análise dos chamados sistemas autopoiéticos sociais por meio de fixação de processo de separação em subsistemas, reconhecendo a existência de organizações e interações, além dos movimentos sociais, que integram os chamados sistemas sociais

O principal fator em comum entre os sistemas sociais é o fato de que a sua operação básica é a comunicação, constituindo-se como uma operação genuinamente social e 
autopoiética porque pode "ser criada somente no contexto recursivo das outras comunicações, dentro de uma rede, cuja reprodução precisa da colaboração de cada comunicação isolada" (LUHMANN, 1980, p. 3).

A teoria luhmaniana também não deixa de levar em conta que fatores como o aumento da complexidade, a existência de organizações, interações e intensificação de movimentos sociais, assim como uma crescente de contingências geram uma pluralidade de expectativas, nascendo a necessidade de um instrumento por meio do qual se torne possível a neutralização de potenciais ações individuais e a viabilidade de expectativa de adição de um comportamento específico por cada indivíduo, criando uma garantia de comportamentos.

Resta, portanto, consagrada a existência de inúmeras contingências que poderiam interferir nas expectativas de cada indivíduo sem a possibilidade de prever quais fatos, instituições, normas ou interpretações (núcleos significativos) por parte dos atores teriam o condão de fazê-lo, oportunidade em que surge a necessidade de que as partes tenham uma mínima previsibilidade de que comportamentos serão adotados no futuro, o que consagra a ideia de que, no âmbito da sociedade, existem normas que são incapazes de prevenir dissabores ou desapontamentos, mas garantem uma expectativa de comportamentos, permitindo que, na hipótese de ocorrência de condutas contrárias ao esperado, a parte que suporta tal ônus possa exercer, a depender da espécie de expectativa, um direito de resistência de forma contrafática.

\section{COMPLEXIDADE, SISTEMA, MUNDO CIRCUNDANTE E MECANISMOS ESTRUTURAIS DE EXPECTATIVAS}

Os Sistemas sociais baseiam-se na existência de complexidade do mundo como destinatária de simplificações, o que nos leva à necessidade e compreensão do que seriam sistemas e meios (mundos circundantes), assim como a interação entre ambos.

Sistema pode ser definido como aquilo que diferencia o entorno do seu ambiente com a compreensão de que este entorno é confuso e dinâmico, com limites passíveis de constantes alterações, existindo uma barreira que diferencia ambos, com a possibilidade de que o entorno possua outros sistemas cuja diferença é baseada na ideia de heterogeneidade no grau de complexidade.

A sua característica fundamental é a chamada auto-referência por meio da qual o ocorre uma definição de si mesmo através de uma operação de diferenciação do mundo circundante baseada num código binário e, a partir de tal seletividade, com diminuição da complexidade com base em dados intrínsecos e efetivação de escolhas de certas possibilidades, permite que o sistema seja, concomitantemente, fechado e aberto, com produção de sua própria estrutura e elementos, determinação de seu estado atual com base nas eliminações de possibilidades feitas em momento anterior e, a partir de então, a possibilidade de tornar-se cognitivamente aberto para ser alvo de estímulos, perturbações e ruídos advindos do mundo circundante com a consequente alimentação de seus elementos internos.

Neste contexto, seria possível afirmar que o objetivo precípuo dos sistemas sociais é a busca da redução da complexidade do mundo através de redução seletiva de possibilidades em comparação com as possibilidades infinitas no mundo circundante.

Fácil, portanto, perceber que a complexidade do mundo é sempre maior do que a complexidade existente no âmbito de um sistema, que por sua vez, necessita de um nível de 
especificidade capaz de viabilizar a redução da referida complexidade no seu próprio meio, como condição de sobrevivência.

O homem vive em um mundo constituído sensorialmente, cuja relevância não é inequivocamente definida através do seu organismo. Desta forma o mundo apresenta ao homem uma multiplicidade de possíveis experiências e ações em contraposição ao seu limitado potencial em termos de percepção, assimilação de informação, e ação atual e consciente. Cada experiência concreta apresenta um conteúdo evidente que remete outras possibilidades que são ao mesmo tempo complexas e contingentes (LUHMANN, 1983, p. $45)$.

A complexidade nada mais significa do que dizer quem sempre existem mais possibilidades atingíveis e concretas do que se pode manejar e efetivamente se concretizar, assim como contingencias seriam possibilidades potencialmente aplicáveis de forma diversa daquela que seria almejada ou esperada, o que, resumidamente, pode-se chamar de risco de desapontamento ou desilusão.

Sobre essa situação existencial desenvolvem-se estruturas correspondentes de assimilação da experiência, que absorvem e controlam o duplo problema da complexidade e da contingencia. Certas premissas da experimentação e do comportamento, que possibilitam um bom resultado seletivo, são enfeixadas constituindo sistemas, estabilizando-se relativamente frente a apontamentos (LUHMANN, 1983, p. 46).

Esse efeito seletivo não apenas é considerado inevitável, mas também construtivo, pois gera a possibilidade de fixação de expectativas no mundo circundante, transformando as formas de seleção comprovadamente eficazes contra desapontamentos em um norte ou significado a ser levado em consideração para experiências futuras.

Além das percepções decorrentes dos demais elementos corriqueiros de irritação dos sistemas pertencentes ao mundo circundante, também merece destaque a presença dos outros homens, denominados, "alter ego", como fontes irradiadoras de ações originais (LUHMANN, 1983, p. 46)

As novas perturbações contribuem para um campo ainda mais acentuado de complexidades e contingências, pois surgem oportunidades de agregar experiências de outros ou de valer-se destas para tornar o próprio horizonte mais amplo com efetivo ganho de tempo, mas, em contrapartida, com aumento do risco, do numero de contingencias e inconfiabilidade.

Em o ambiente de crescente complexidade, número de contingencias e perturbações, poderiam surgir especulações quanto à chegada a um ponto de instabilidade, dadas as tensões e expectativas alvo de desilusão, com a agravante de que determinados comportamentos desilusórios tornam-se exteriorizados e visíveis.

Entretanto, tais hipóteses não seriam alvo de um único desfecho, pois a depender das expectativas contrariadas, poderíamos nos deparar com a conduta de conformação à nova realidade, com aceitação do novo panorama, e adaptação à desilusão ou com o exercício da resistência em face da realidade contrastante, o que nos abriria a possibilidade de tratar de duas espécies de expectativas, quais sejam, as cognitivas e as normativas. 
Esta classificação das expectativas não passa por uma interpretação baseada no pragmatismo, mas possui um acentuado viés funcional e utilitarista, baseado na busca de solução de problemas específicos. Senão vejamos:

Ela aponta para o tipo de antecipação da absorção de desapontamentos, sendo assim capaz de fornecer uma contribuição essencial para o esclarecimento dos mecanismos elementares de formação do direito. Ao nível cognitivo são experimentadas e tratadas as expectativas que, no caso de desapontamentos, são adaptadas à realidade. Nas expectativas normativas ocorre o contrário: elas não são abandonadas se alguém as transgride (LUHMANN, 1983, p. 56).

Neste cenário, poderíamos denominar as normas como padrões de comportamento estipulados que podem, a depender do cumprimento ou não de suas disposições no mundo fenomênico, assumir um caráter contrafático, ou seja, não está vinculada à realização no mundo fenomênico.

A chamada normatização acaba conferindo uma noção de perenidade não vinculada a uma eventual frustração, criando uma institucionalização e um consenso geral que despreza noções de aprovação individual. Neste contexto, podemos utilizar as palavras de Luhmann no sentido de que "dessa forma a generalização gera uma imunização simbólica das expectativas contra outras possibilidades; sua função apoia o necessário processo de redução ao possibilitar uma indiferença inofensiva" (LUHMANN, 1983, p. 110).

\section{DIREITO, LEGALIDADE E AUTOPOIESE}

Para Luhmann, as normas, instituições e os sentidos (denominados núcleos significativos) não são congruentes, ou seja, não promovem uma uniformização quanto às expectativas de forma linear, pois nem sempre são compatíveis entre si, o que transforma o direito numa ferramenta de compatibilização e de generalização de forma ordenada, viabilizando a imunização de certas expectativas para moldar determinados fatos, possibilitando, a depender da espécie de expectativa, a adoção de uma conduta que não se limite nem dependa do que realmente acontece no mundo fenomênico (LUHMANN, 1980, p. 3).

O comportamento social em um ambiente dotado de alta complexidade tende a promover reduções imprescindíveis para a realização de expectativas de comportamento que tendem a se orientar com base nas expectativas das expetativas e que se subdividem com base nas dimensões temporais, sociais e práticas (LUHMANN, 1983, p. 109).

Esta distancia de natureza paralela entre os conceitos e as dimensões acima citadas geram a necessidade de normatização como forma de contornar os diferentes critérios e as exigências altamente heterogêneas das dimensões, dando origem a uma expectativa contínua, buscando o tão almejado consenso geral suposto e a imunização simbólica outrora citados neste ensaio.

Não existe, portanto, uma verdade genuína, mas sim uma continua generalização de expectativas com a finalidade de promover uma diluição de tais diferenças através da produção de normas de cunho individual ou universal na busca de uma institucionalização, o que nem sempre ocorre. 
O direito acaba sendo compreendido com uma função utilitarista baseada em pressupostos fáticos com a característica não apenas de um ordenamento baseado na coação e sanções, mas também num amortecedor de expectativas tornando a possibilidade de exercício e manifestação de outras possibilidades numa aparente inofensividade, minimizando o impacto das condutas com potencial para desiludir expectativas.

Seria o direito dotado de uma função precípua de caráter seletivo com eleição comportamental que abarcaria as três dimensões, quais sejam, temporais, sociais e práticas, com adoção de determinados comportamentos uniformes como padrões de evolução do direito e como elemento de atuação diante das alterações do sistema social quando de sua evolução histórica (LUHMANN, 1983, p. 116).

Também merece destaque a necessidade de estabelecimento de normas para que a seleção de expectativas buscada pelo direito possa alcançar seu objetivo final, o que torna tal procedimento suscetível a interferências externas e, nas palavras de Luhmann, desperta a necessidade de um certo isolamento do rito a ser adotado para garantia de tratamento de uma determinada disposição com natureza de norma em todos os seus aspectos, inclusive nos processo de decisão jurídica em que tal norma seja invocada, o que assegura a estabilidade em caso de condutas potencialmente frustrantes de expectativas. (LUHMANN, 1985, p. 18).

A alta complexidade e a variabilidade de expectativas acabam por repercutir não apenas no campo da política, cronologicamente prévio à formulação de normas jurídicas e de seleção do direito, mas também na sua positivação e na estrutura da sociedade, pois não há discussão sobre a importância da regulação na busca de estruturas comportamentais generalizadas de forma congruente com a constatação de que normas jurídicas não são apenas programáticas e voltadas para determinadas ações, mas sim comandos de natureza mais ampla e voltados para todos os integrantes quando da interação e comunicação social (LUHMANN, 1985, p. 53).

Neste cenário, a positivação do direito e sua repercussão na legalidade permanecem condicionadas às mudanças sociais, sobretudo num cenário de acentuada complexidade, com um viés crescente de tal tendência e com o surgimento de novos problemas e impasses a serem conformados pela ordem jurídica que, por sua vez, apresenta uma infinidade de possibilidades quanto à forma de solução.

A consequência de tal panorama é a diferenciação funcional como instrumento de criação de sistemas parciais voltados para solucionar impasses específicos com uma fixação dinâmica de quais seriam os problemas pendentes de solução com destaque para diferenciações cada vez mais abstratas, dotadas de um risco disseminado, interdisciplinar e com clara interdependência entre os sistemas (político, econômico, legislativo, etc) com possibilidades que só podem se realizar de forma parcial, marcadas pela crescente necessidade do que Luhmann convencionou chamar de processo de seleção consciente (LUHMANN, 1983, p. 225).

Outra característica relevante a ser mencionada e muito enfatizada na teoria luhmaniana dos sistemas é a chamada autopoiese, inicialmente mencionada no campo da biologia através de Maturana e Varela (MATURANA; VARELA, 1995, p. 88), mas adotada na teoria dos sistemas, atribuindo a este a qualidade de ser simultaneamente fechado e aberto com relevante repercussão nos campos da política, jurídico e nas questões relacionadas ao sistema democrático. 
Com as adaptações impressas por Luhmann, a teoria dos sistemas é marcada pela universalidade, com limites que desconhecem apenas o campo da sociologia, assim como epistemológico, baseado na existência com a finalidade de resolução de um problema a ser definido pelo sistema e cuja satisfação define a subsistência do mesmo.

João Paulo Allain Teixeira, ao citar Marcelo Neves (1994 apud TEIXEIRA, 2009, p. 313-324), reitera a tese de que a principal diferença entre a autopoiese biológica e a social seria o fato de a primeira apregoar uma concepção radical do fechamento com a exigência de um observador externo (outro sistema) para viabilizar a produção de relações entre o sistema e seu entorno, enquanto que os sistemas sociais seriam dotados de uma auto-observação como condição sine qua non para a chamada reprodução autopoiética.

Além disso, a característica da auto-referencia nos transpassa a realidade de que o sistema é baseado em sua própria análise e se define como tal a partir de sua diferenciação frente ao entrono ou mundo circundante, dando origem a operações especificas após a sua formação, baseadas, num primeiro momento, na observação através da qual se utiliza de um código binário para análise de ruídos e irritações com a utilização do próprio sistema como parâmetro para aferir os valores e, concomitantemente, exercer a auto-observação (análise de critérios internos) e a hetero-observação (observação dos elementos que compõem o entorno ou mundo circundante), o que jamais inviabiliza a observação inter sistemas que também podemos chamar de hetero-referência (também se torna objeto de observação de outros sistemas) com a possibilidade de utilização da seletividade para reduzir o plexo de contingências e a respectiva complexidade do mundo circundante.

Tem-se, portanto, um sistema chamado autopoiético quando se evidenciar capaz de reprodução baseada em seus próprios elementos e códigos internos com expressão da autonomia nas reduções de expectativas e seleção das interferências externas.

Neste contexto, o processo de leitura do meio-ambiente baseia-se num processo de análise deste com utilização do chamado código binário como parâmetro ou filtragem, pois só assim determinada irritação ou informação encontrada poderá ser incorporada ao sistema após avaliada pelos critérios do próprio sistema através de uma observação ou leitura e posterior absorção através do código licitude/ilicitude (LUHMANN, 2007, p. 44).

Nas palavras de João Paulo Allain "os subsistemas sociais diferenciam-se com o advento da Modernidade a partir do desenvolvimento de seus próprios critérios internos de seletividade. A partir do desenvolvimento do código binário, o subsistema afirma-se diante dos demais como subsistema verdadeiramente autônomo" (TEIXEIRA, 2009, p. 320).

O código binário com qualidade intra-sistêmica torna o sistema autônomo, pois atua através do fechamento operacional do sistema e concomitante abertura cognitiva, ou seja, as irritações e informações que se encontram no entorno podem ser observadas, lidas e incorporadas desde que aprovadas pela seletividade estabelecida internamente.

Paulo Barros de Carvalho assinala que a definição de sistema deve ser encarada como um conjunto de objetos com características comuns e dotados de uma relação de coordenação e subordinação que, além de conectados entre si, possuem a indispensabilidade da linguagem para a sua formação (CARVALHO, 2009, p. 115).

Importante salientar que Luhmann reconhecia a impossibilidade de atuação dos sistemas além de seus limites, assim como reconhecia não existir indiferença em relação aos elementos externos ou circundantes, aliados ao reconhecimento de que nenhum sistema evolui a partir de si mesmo (LUHMANN, 2002, p. 91). 
As perturbações externas são essenciais para desequilibrar o sistema e dar ensejo à sua evolução com ênfase no fenômeno do acoplamento estrutural como forma de justificar a possibilidade de atuação frente ao mundo circundante (LUHMANN, 2002, p. 110).

Luhmann, ao mencionar o chamado código binário, se baseia numa integração entre o passado e as decisões e probabilidades futuras com a aferição de sentido das decisões a ser observado em momento posterior com desprezo quanto à importância quanto à essência das decisões e de seus efeitos (LUHMANN, 2002, p. 248).

Neste contexto, João Paulo Allain afirma que "em Luhmann não há propriamente uma fundamentação do direito, mas o resultado de um processo evolutivo que culmina com a afirmação do código binário que atua com crivo de seletividade e estabilização de expectativas normativas" (TEIXEIRA, 2009, p. 320).

Também é importante mencionar que as noções de licitude e ilicitude, decorrem de um constante processo de comunicação no interior do subsistema decorrentes das influências e informações advindas do mundo circundante, geralmente compostas pela lei, jurisprudência e demais formas de comunicação (TEIXEIRA, 2009, p. 320).

\section{POLÍTICA E CONSTITUIÇÃO SOB O ENFOQUE DA TEORIA DOS SISTEMAS}

A política se constitui como um dentre vários subsistemas, também dotada de códigos próprios com funções intra sistêmicas e atuação na sociedade, consubstanciado no binário governo/oposição com a tarefa de acumular a formação das opiniões públicas com vinculação coletiva.

Neste contexto, a Constituição se define como o produto do acoplamento estrutural entre o Sistema do Direito e aquele pertinente à Política com a afirmação de que o Direito desponta como um instrumento de resolução temporal da comunicação social, o que vincula sua função com a existência de expectativas e de comunicações. (LUHMANN, 2002, p.187)

Com base em tal premissa e na existência de repetições com estabilização de expectativas com caráter normativo, ou seja, dotadas de caráter contrafático, Luhmann afirma ser esta a característica que determina a diferenciação dos Sistemas Jurídico e Político, com ênfase na constatação de que o Direito possui relação de dependência junto à Política e a estabilidade normativa está condicionada à existência de uma imposição, assim como o Direito se constitui na diversificação de manifestações de poder utilizadas pela mesma Política. (LUHMANN, 220, p. 207-208).

As manifestações políticas de uma decisão com efeito vinculante e coletivo converte os pleitos sociais e decisões viáveis com possibilidade de fazer-se cumprir, entretanto não existe a chamada superioridade ou degrau mais alto de poder quando à obrigatoriedade das normas, o que faz com que a Teoria dos Sistemas ganha ênfase quando da análise do conceito de Constituição.

Não há um consenso quanto à definição de Constituição, pois mesmo entre operadores do Direito e cientistas na seara forense não existe uma definição capaz de conter as opiniões de forma hegemônica, seja porque se mostra com a intenção de universalidade, o que rompe com a tradição das formas normativas anteriores, seja porque busca uma sobreposição do Direito positivo sobre o natural. (CORSI, 2001, p. 169)

Luhmann definia Constituição como uma reação à distinção entre Direito e Política, afirmando uma necessidade de ligação entre ambos e, nas palavras de Giancarlo Corsi, um 
acoplamento estrutural entre os dois sem deixar de reconhecer que são sistemas autônomos com possibilidade de irritações recíprocas. (CORSI, 2001, p. 172-173)

Nas palavras de Luhmann, o Direito poderá formular seu próprio código binário com a criação de uma identidade própria através da positivação, pois, neste panorama, o direito só pode ser criado pelo próprio direito e não por uma vontade política, pois a linguagem veiculada expressa a chamada autodeterminação do sistema jurídico no campo operacional, destacada a impossibilidade do fundamento de validade oriundo de ato político (LUHMANN, 1996, p. 04).

Já a seara da Política possui como traço característico ter a Constituição como um instrumento de fundamentação do exercício da soberania por meio da qual existirá uma discussão acerca de quais decisões a serem tomadas serão vinculantes ou não.

Não é ignorado que, à semelhança do sistema jurídico, o político também se utiliza do procedimento da autoreferenciabilidade, mas o efeito vinculante ocorre a partir do momento em que aquele que decide ou que é dotado de poder de decisão integra o referido sistema.

Neste contexto, ganha importância um acoplamento estrutural entre Direito e Política via Constituição, pois ocorre uma harmonização de autoreferenciabilidade da Política com a Constituição, e adoção por parte daquela do Direito como instrumento capaz de conferir (pretensa) concretude às decisões.

É justamente a ausência de congruências, ou seja, ausência de sobreposição, que permite a utilização do Direito por parte da Política de acordo com o que Luhmann convencionou chamar de heteroreferenciabilidade. (LUHMANN, 1996, p. 10)

Tal modus operandi é de grande relevância para definir Estado através de uma variabilidade de conceitos de acordo com o sistema que for adotado como referencial, inclusive com a importância reconhecida do controle de constitucionalidade como forma de manutenção desse acoplamento estrutural e mediador dos dois Sistemas do Direito e da Política, destacando-se a posição dos Tribunais ao analisar as condições de validade e de conformação com a Constituição como indicadores do código binário licitude/ilicitude (PINTO, 2004, p.149).

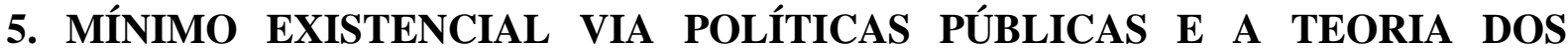 SISTEMAS}

É relevante reconhecer que o Estado tem como uma de suas finalidades primordiais o alcance da inclusão do indivíduo à sociedade através de políticas públicas de cunho social e econômico com a finalidade de realização do mínimo existencial e da possibilidade de garantir às pessoas condições mínimas para que possam atuar com cidadania plena.

O mínimo existencial possui fundamento no princípio da dignidade da pessoa humana, implicando em obrigação estatal de provê-lo ainda que a Carta Constitucional de um determinado Estado não possua um rol expresso de direito fundamentais de cunho social, o que foi adotado por países como Alemanha, por exemplo, tratando-se, portanto, de um direito subjetivo na forma de ajuda ou prestação material a ser fornecida pelo Estado. Nesta perspectiva decidiu o Tribunal Federal Constitucional da Alemanha tratar-se de um dever estatal elementar.

Com certeza a assistência social aos necessitados faz parte dos deveres mais evidentes de um Estado social. Isto inclui necessariamente a ajuda social do cidadão que, em razão de deficiência física ou mental, tem seu 
desenvolvimento pessoal e social impedido, sendo incapaz de prover seu próprio sustento. A sociedade estatal deve, em todo caso, garantir-lhe condições mínimas para uma existência humanamente digna, e deve, além disso, esforçar-se para, na medida do possível, incluí-lo na sociedade, estimular se adequado tratamento pela família ou por terceiro, bem como criar as necessárias instituições de cuidado (CORDEIRO, 2012, p. 104 apud MARTINS, 2005, p.828).

Restou assentado, portanto, que o mínimo existencial seria um direito fundamental com raízes no princípio da dignidade da pessoa humana, direito à vida, igualdade e integridade física, tornando-se tal entendimento jurisprudencial em um vetor para o tratamento desta matéria não apenas em boa parte dos ordenamentos europeus, mas também na América do Sul, inclusive o Brasil, ainda que tenha adotado um caminho diferente do ordenamento alemão, com a constitucionalização expressa de direitos sociais.

Nesta esteira, o mínimo existencial seria uma condição prévia e essencial para o exercício dos demais direitos, considerado um núcleo indisponível de direitos sociais, com caráter de standard mínimo de existência indispensável a qualquer direito. (CANOTILHO, 2006, p. 518).

A Constituição brasileira de 1988, por sua vez, não proclama de forma expressa o mínimo existencial, mas adota disposições de exercício de direitos sociais em inúmeras passagens de seu texto, incluindo o preâmbulo, os arts. $1^{\circ}$, III, $3^{\circ}$, III e 170 , além de um extenso rol de direitos sociais com enumeração específica e com o objetivo de garantia de uma participação efetiva nos rumos da sociedade e na própria qualidade de vida, nos arts $6^{\circ} \mathrm{e}$ $7^{\circ}$ do texto constitucional nacional. (SARLET, 2009, p. 317).

Daniel Sarmento, ao tratar do tema, afirma que existe a necessidade de uma correta interpretação e atenta para o fato de que "uma compreensão correta da ideia de justiça teria de envolver a obrigação moral do Estado e da sociedade de combater o sofrimento e a miséria humanas, através da garantia de condições mínimas de vida para os necessitados". (SARMENTO, 2009, p. 533-586).

A doutrina e jurisprudência brasileiras não possuem uma fundamentação uníssona do mínimo existencial, restando apenas um consenso de que foi acolhido na Constituição de 1988 como um direito fundamental com a definição de "conjunto das condições primárias sócio-políticas, materiais e psicológicas sem as quais não se dotam de conteúdo próprio os direitos assegurados constitucionalmente" (CORDEIRO, 2012, p. 108).

A compreensão do termo mínimo existencial passa pela ideia de valor absoluto da pessoa humana e, concomitantemente, de requisito indispensável para o exercício efetivo das liberdades materiais e viabilidade da democracia na qual a qualidade de seus integrantes possui direta repercussão na consolidação das vontades e no exercício da cidadania no âmbito social (CORDEIRO, 2012, p. 110).

Outro aspecto relevante a ser destacado seria a repercussão do reconhecimento do mínimo existencial como um direito fundamental e sua exigibilidade na seara administrativa e em juízo, na hipótese de omissão estatal do dever de fornecer a respectiva prestação material, pois a complexidade da tarefa de definição dos contornos do referido instituto possui direta repercussão na maneira de disponibilidade por parte do Estado. (CORDEIRO, 2012, p. 110).

A amplitude e os aspectos qualitativos e quantitativos, somada ao pluralismo inerente à sociedade contemporânea acabam por criar uma atmosfera de grandes controvérsias e 
incertezas, sobretudo quando nos deparamos com conceitos como direitos fundamentais sociais e sua parcela indisponível, separação de poderes, ativismo judicial, escolhas quanto à forma de implementação pelos democraticamente eleitos e disposições legislativas que determinem o rito de efetivação, o que nos coloca diante de um sem fim de contingências e expectativas dentro deste sistema de implementação de garantias e direitos notadamente relacionados à afirmação do ser humano como centro do ordenamento jurídico.

Ao falarmos em parcela indisponível dos direitos sociais, surge a necessidade destacar um conteúdo ou conjunto de prestações que não são suscetíveis a intervenções ou omissões estatais quanto à forma de efetivação, constituindo-se no que podemos chamar de "um conjunto de bens diferenciado, absolutamente removido do processo de ponderação". (SARLET, 2009: 402) Seria um espaço ou plexo de prestações materiais que o Estado possui o dever incondicional de disponibilizar (CORDEIRO, 2012, p. 112).

Tal tarefa é carregada de grande complexidade, haja vista despontarem inúmeras teorias com a finalidade de determinação de um conteúdo mínimo e que se dividem, ora na fixação de um patamar abstratamente definido, como se existisse em cada direito duas parcelas separáveis na forma de um núcleo essencial e uma medida acessória, ora baseado na necessidade de utilização da proporcionalidade para decidir de acordo com o caso concreto a esfera indisponível de cada direito elencado (CORDEIRO, 2012, p. 113).

Canotilho também destaca a existência das teorias objetiva e subjetiva. A primeira destaca o objeto da proteção na forma da eficácia e supremacia do próprio texto constitucional através da preservação de seus princípios explícitos e implícitos e de um rol de direitos sociais (caso a Constituição do Estado tenha adotado tal metodologia de explanação de rol de direitos), já a segunda categoria está baseada na ideia de proteção de cada indivíduo de forma especifica, com olhos voltados para as necessidades individuais que as circunstâncias fáticas e jurídicas pessoais apresentarem (CANOTILHO, 2006, p. 459-460).

Também merece destaque a teoria mista, marcada pela procura de uma parcela essencial no caso concreto e que, doravante, passa a ser aplicado aos casos semelhantes com caráter quase absoluto, com a nítida intenção de harmonizar as teorias do parágrafo anterior, promovendo, concomitantemente, a defesa da supremacia da Constituição e da esfera e individual do cidadão por entender que as duas proteções não são excludentes, mas complementares (CANOTILHO, 2006, p. 461).

Tais teorias, em que pese a importância de cada um dos raciocínios jurídicos explanados, não são capazes de criar um consenso no âmbito doutrinário e jurisprudencial, haja vista a complexidade e o caráter contingente deste sistema de garantias tão específico, diverso do sistema jurídico, com constantes irritações e informações em decorrência da natureza do bem jurídico tutelado no caso concreto, possível existência de um rito legislativo positivado para regular eventual implementação de um direito social, estágio de desenvolvimento econômico e cultural de uma determinada sociedade, judicializações de políticas públicas, entre outros inúmeros fatores, cuja previsão se mostra impossível em sua totalidade, exigindo constante especificação na busca da efetivação de tais prestações materiais

Resta evidenciada, portanto, a existência de uma pluralidade de subsistemas autopoiéticos como políticas públicas, direito, economia, orçamento público, todos marcados pela chamada semiótica, ou seja, a linguagem seria a forma dos atos de comunicação para interpretar os elementos de cada sistema. 
Paulo Barros de Carvalho sintetiza a proposição supracitada ao conferir autonomia ao sistema do Direito, pois na ótica autopoiética de Luhmann enfatiza uma abertura de caráter pragmático.

a dinâmica operacional do direito se dá pela combinatória dos três modais (permitido, proibido e obrigatório). Como são três (lei do quarto excluído), concluímos que há fechamento sitático. Entretanto, estando as hipóteses normativas sempre prontas para receber novos fatos que o legislador entenda relevantes, como portas abertas para a absorção de matérias sociais, políticas, econômicas, morais, etc., teríamos abertura na dimensão pragmática (CARVALHO, 2010, p. 159).

Ao destacarmos o mínimo existencial como um direito social fundamental, o sistema social relacionado às políticas públicas de implementação de direitos sociais possui como enfoque principal a dignidade da pessoa humana acompanhado da necessidade de especificação de valores formulados e assegurados quando da promulgação da constituinte de 1988.

Ao tratarmos do direito à saúde, por exemplo, podemos facilmente constatar que foi consagrado como um direito fundamental social com previsão nos art. $6^{\circ}, 7^{\circ}$ e 196 da Constituição de 1988, apontado pelo respectivo constituinte como um sistema social de política pública com um código binário próprio baseado na noção de acesso ou ausência de acesso.

Trata-se, portanto, de uma expectativa normativa quanto à prestação do direito à saúde, pois diretamente relacionado, nas palavras de Ingo Sarlet, à noção de direitos humanos e direitos fundamentais, com albergue em tratados e convenções internacionais, pretensão de universalidade, assim como previstos e positivados na orbita interna estatal (SARLET, 2013, p. 260-263).

Este direito acompanhado da implementação de políticas públicas está sujeito às contingências decorrentes da subjetividade inerente às necessidades individuais com acentuada e crescente complexidade intra sistêmica e da necessidade de acompanhamento da evolução de outros sistemas autopoiéticos relacionados à evolução da ciência, nível socioeconômico de uma determinada sociedade, reservas orçamentárias, interferências de laboratórios médicos e suas duvidosas relações com atores das áreas de saúde, formas equivocadas de implementação de políticas públicas pelos órgãos e entidades estatais, decisões judiciais que tutelam o custeio de tratamentos individuais que acabam comprometendo o custeio de ações de saúde direcionadas a uma infinidade de indivíduos, corroborando com o pensamento sistêmico de Niklas Luhmann e a existência de inúmeros conflitos ou contingências.

Por outro lado, existem padrões objetivos mínimos que merecem uma especial atenção do Poder Público quando da elaboração de diretrizes para a implementação de políticas públicas com destaque para aquelas consagradas no texto constitucional como ações de saúde preventiva, saneamento básico e previsões nos arts. 198, II, 200, II e IV e $227, \S^{\circ}$ da Constituição de 1988.

Tais limites não excluem a característica da complexidade e da interdisciplinariedade de sua efetivação decorrente da existência de vários sistemas autopoiéticos envolvidos na prestação estatal e que devem ser analizados na qualidade de entorno ou mundo circundante, 
de forma recíproca, para fins de acoplamento estrutural e tomada de decisões em harmonia com o crescente caráter evolutivo da sociedade (LUHMANN, 2002, p. 236).

Considerada a política pública como um sistema autopoiético, sobretudo quando da implementação do mínimo existencial, fundado na prestação material fornecedora de parâmetros mínimos para uma vida digna para o exercício da cidadania que possibilite uma participação qualitativa na vida pública e na consecução de seus próprios destinos , desponta a teoria luhmaniana dos sistemas como forma de adoção de um código binário de prestação ou não prestação com constantes irritações decorrentes de variáveis externas não pertencentes ao sistema em constantes alterações decorrentes da evolução das necessidades da coletividade e da natureza das políticas públicas.

\section{CONSIDERAÇÕES FINAIS}

Uma análise da Carta Magna passa pela constatação de que vivemos, antes de tudo, numa sociedade sistêmica e funcional com comunicações baseadas em códigos binários, dando ensejo ao que podemos denominar sistemas parciais que, por sua vez, dão origem a subsistemas umbilicalmente ligados à atividade de especificação das contingências e filtro das irritações com base no código binário respectivo.

Nos sistemas político e jurídico, integrados respectivamente pelo binômio poder/não poder e licitude/ilicitude, as seleções internas decorrentes da atuação do sistema político possuem eficácia vinculante dentro do seio social com a edição de diplomas normativos legais e infralegais e recepção de tais valores por parte do sistema jurídico que, por sua vez, atua com base em tais legislações e trabalha com o objetivo de conferir estabilidade às expectativas normativas contrafáticas.

A Constituição é um acoplamento estrutural com grande repercussão no sentido de harmonizar os sistemas político e jurídico, pois inclui novos valores a serem observados através de irritações a ambos os sistemas e através de novos mecanismos baseados na comunicação, oportunidade em que também introduz novos elementos baseados na sociologia, economia, filosofia, entre outras ciências, na forma de sistemas parciais sujeitos a um mecanismo de interpretação contínuo e diuturno com repercussão de suas influências recíprocas e um filtro levado a cabo pelos respectivos códigos binários.

$\mathrm{Na}$ seara jurídica, um problema do ambiente selecionado por sua estrutura intra sistêmica se submete a uma leitura de um código exclusivo de licitude/ilicitude com o chamado fechamento operacional, mas com uma abertura cognitiva em relação ao entorno ou mundo circundante, o que pode ser evidenciado pela chamada inafastabilidade de jurisdição que imprime a obrigação de decidir e de dar uma resposta utilizando-se de seus elementos intra sistêmicos com uma consequente especificação de operações internas para exteriorizar as respostas aos problemas trazidos, decorrendo daí, a chamada abertura cognitiva.

Os conflitos de cunho político que surgem e são submetidos ao crivo do sistema jurídico, na forma de provocação dos Tribunais ou órgãos judiciários, só serão resolvidos ou pretensamente solucionados através do código binário licitude/ilicitude com soluções legais para conflitos, irritações ou problemas de cunho político que passam por uma adaptação e tradução intra sistêmica, não sendo um objetivo do sistema jurídico, em tese, buscar conformações políticas, mas tão somente a estabilidade das expectativas. 
O sistema político, por sua vez, também é parcial, integrante do sistema maior sociedade, com estruturas singulares, autônomo e com a capacidade de tomar decisões de acordo com código (governo/oposição) e elementos próprios, com função de garantir a tomada de decisões com efeito vinculante e coletivo e abrangendo uma relação de hierarquia, marcada por aqueles que são detentores de cargos e aqueles que são administrados e oposição, com continuidade da comunicação através dos periódicos processos eleitorais que também funcionam como instrumento de legitimação.

A Constituição desponta, neste contexto, como um liame fundamental para que o sistema jurídico e político promovam uma constante irritação recíproca com capacidade de aprendizado, o que, na prática, contribui para amenizar as controvérsias decorrentes da zona cinzenta existente entre o mínimo existencial inerente aos direitos fundamentais de cunho social, matéria de natureza eminentemente política, e a atividade jurisdicional de controle de constitucionalidade e de prestação jurisdicional de obrigações de fazer ou não fazer em face da inafastabilidade de jurisdição sempre que houver violação por ação ou omissão estatal de parcela dotada de caráter de direito subjetivo, exigível em juízo e dotada de parâmetros mínimos quanto à prestação material garantidora de vida digna e exercício da cidadania.

\section{REFERÊNCIAS}

CANOtilho, José Joaquim Gomes. Direito Constitucional e Teoria da Constituição. 7.ed.,2. reimp. Coimbra: Alemdina, 2006.

CARVALHO, Paulo Barros. Curso de Direito Tributário. $22^{a}$ edição. São Paulo: Saraiva. 2010.

edição. São Paulo: Noeses, 2010.

Paulo Barros. Direito Tributário, Linguagem e Método. $3^{\mathrm{a}}$

CORDEIRO, Karine da Silva. Direitos fundamentais sociais: dignidade da pessoa humana e mínimo existencial, o papel do poder judiciário. Porto Alegre: Livraria do Advogado, 2012.

CORSI, Giancarlo. Sociologia da Constituição. Trad. Juliana Neunschwander Magalhães. In: Revista da Faculdade de Direito da UFMG. Belo Horizonte. n. 35. jan.-jun./2001.

CHAUÍ, Marilena. Público, Privado, Despotismo. In: NOVAES, Adalto (org.) Ética. São Paulo: Companhia das Letras, 1992.

LUHMANN, Niklas. Legitimação pelo procedimento. Trad. de Maria da Conceição CôrteReal. Brasília. Editora Universidade de Brasília, 1980.

Sociologia do Direito I. Trad. de Gustavo Bayer. Rio de Janeiro: Ediçoes Tempo Brasileiro, 1983.

Sociologia do Direito II. Trad. de Gustavo Bayer. Rio de Janeiro: Edições Tempo Brasileiro, 1985.

El Derecho de La Sociedad. Trad. Javier Torres Nafarrate. México:

Universidad Ibertoamericana, 2002

Introducción a La teoria de sitemas. Lecciones publicadas por Javier Torres Nafarrate. 1. Reimpressión. Lomas de Santa Fé, Mexico: Universidad Iberoamericana, 2002.

MARTINS, Leonardo (Org.). Cinquenta anos de jurisprudência do Tribunal Constitucional Federal Alemão. Montevideo: Foundación Konrad-Adenauer, 2005. 
MATURANA, Humberto; VARELA, Francisco. A árvore do conhecimento: as bases biológicas do entendimento humano. Tradução de Jonas Pereira dos Santos. Campinas: Workshopsy, 1995.

NEVES, Marcelo. Constitucionalização Simbólica. São Paulo: Acadêmica, 1994.

SARLET, Ingo Wolfgang. A eficácia dos direitos fudamentais: uma teoria geral dos direitos fundamentais na perspectiva constitucional. 10. Ed. rev. atual. e ampl. Porto Alegre: Livraria do Advogado, 2009.

SARLET, Ingo Wolfgang; MARINONI, Luiz Guilherme; MITIDIERO, Daniel. Curso de Direito Constitucional. 2. ed. São Paulo: Editora Revista dos Tribunais, 2013.

SARMENTO, Daniel. A proteção judicial dos direitos sociais: alguns parâmetros éticojurídicos. In: ARRUDA, Paula (Coord.) Direitos Humanos: questões em debate. Rio de Janeiro: Lumen Juris, 2009.

TEIXEIRA, João Paulo Allain . Direito e Política na Teoria dos Sistemas. In: Sociedade, Direito e Decisão em Niklas Luhmann, 2009, Recife. Sociedade, Direito e Decisão em Niklas Luhmann - Anais. Recife: Editora Universitária - UFPE, 2009. 